\title{
Erratum
}

MELIKŞAH DEMIR and LESLEY A. WEITEKAMP

\section{AM SO HAPPY 'CAUSE TODAY I FOUND MY FRIEND: FRIENDSHIP AND PERSONALITY AS PREDICTORS OF HAPPINESS}

\section{Journal of Happiness Studies \\ DOI 10.1007/s10902-006-9012-7}

Concerning the article:

With reference to the Abstract:

Please note that in the abstract the sentence

'Friendship variables accounted for $58 \%$ of the variance in happiness'

Should read:

'Study variables accounted for $58 \%$ of the variance in happiness'.

The online version of the original article can be found at http://dx.doi.org/ $10.1007 /$ s10902-006-9012-7 